\title{
O EMBATE DE SENTIDOS DO TERMO PROFESSOR: UMA ANÁLISE SEMÂNTICA DE PROPAGANDAS VEICULADAS PELO MEC
}

\author{
Lívia Cristina de Souza Sigliani \\ Mestranda em Linguística pela Universidade Estadual do Sudoeste da Bahia (UESB) \\ [Bolsista CAPES] \\ lisigliani@gmail.com \\ Adilson Ventura da Silva \\ Doutor em Linguística pela Universidade Estadual de Campinas (UNICAMP) \\ Professor Adjunto da Universidade Estadual do Sudoeste da Bahia (UESB) \\ adilson.ventura@gmail.com
}

\section{RESUMO}

O objetivo deste trabalho é discutir por meio da análise de três propagandas veiculadas pelo Ministério da Educação MEC, os sentidos do termo professor e como o político se configura nessas relações de sentido sob a perspectiva da Semântica do Acontecimento, teoria que parte do pressuposto da enunciação como um acontecimento de linguagem que produz sentido a partir de uma relação do sujeito com a língua, sendo essa relação prática política, pois instaura o conflito no centro do dizer. Os sentidos não são fixos nem estanques, pois são constituídos na enunciação e não são transparentes, pois o sujeito não tem controle sobre os sentidos. Nossa hipótese é a de que os sentidos de professor não remetem somente ao profissional e que ao passo que sentidos de prestígio são constituídos, sentidos de desvalorização também são percebidos nesses enunciados. Como resultado, percebemos a presença constante do conflito de sentidos em nossas análises.

Palavras-chave: político; professor; propaganda; semântica do acontecimento.

\section{ABSTRACT}

The aim of this paper is to discuss through the analysis of three advertisements published by the Ministry of Education MEC, the meanings of the term teacher and how the politician configures itself in these relations of meaning from the perspective of the Semantic of Event, a theory that starts from the assumption of enunciation as an event of language that produces meaning from a relationship between the subject and language, and this relationship is practical political, because it establishes conflict at the center of speech. The senses are neither fixed nor watertight, since they are constituted in the utterance and are not transparent, because the subject has no control over the senses. Our hypothesis is that the teacher's senses do not refer only to the professional and that while prestigious meanings are constituted, meanings of devaluation are also perceived in these statements. As a result, we realize the constant presence of conflict of meaning in our analyzes.

Keyworks: political; teacher's senses; marketing; semantics of the event. 


\section{Considerações iniciais}

Ao analisarmos os sentidos de "professor", objetivo precípuo de nossa pesquisa de mestrado por ora intitulada Desvalorização, reconhecimento ou dom? Uma análise dos sentidos de professor, observamos em diversas materialidades significantes um embate de sentidos. Percebemos que, na medida em que a importância da profissão docente é reconhecida, sentidos de desvalorização do professor também são comumente percebidos. Ao mesmo tempo em que é considerado importante, o professor é desvalorizado e esses sentidos estão constituídos em uma série de materialidades com diversos fins.

A partir dessas observações, propomos uma análise do termo "professor" em três peças publicitárias veiculadas pelo Ministério da Educação - MEC, visto que o MEC é o órgão da administração federal direta responsável pelas políticas educacionais. Além disso, levamos em consideração a importância da mídia para a constituição e circulação desses sentidos.

De acordo com Payer (2005), a teoria do discurso considera que os discursos, materializados em textos que circulam nas práticas sociais, desempenham um papel decisivo na constituição do sujeito na sociedade. Para a autora, a linguagem tem uma relação muito estreita com o sujeito e, por isso, é importante que se compreenda essa relação para entender muito do que se passa com o sujeito e com a sociedade. $\mathrm{Na}$ sociedade contemporânea, o texto a constituir o sujeito é o texto do mercado, que ganha valor de texto fundamental e a mídia, por sua vez, funciona como texto fundamental do mercado. 
Para analisarmos como esses sentidos se constituem, lançaremos mão da teoria da Semântica do Acontecimento (SA), e mobilizaremos alguns de seus conceitos fundamentais, como os conceitos de político e de temporalidade. Nosso escopo teórico parte do pressuposto da não transparência da língua e que os sentidos se dão na enunciação, no acontecimento do dizer.

Para a SA, os sentidos são constituídos numa relação da língua com a própria língua, porém essa relação é tomada na História. A enunciação consiste em uma relação do sujeito com a língua, sendo uma prática política, pois instaura o conflito no centro do dizer. Vários Grupos de pesquisa brasileiros desenvolvem a SA, inclusive na UESB Universidade Estadual do Sudoeste da Bahia - onde trabalhos de grande relevância são desenvolvidos pelo GEPES - Grupo de estudos e pesquisa em semântica, que trabalha com a análise da constituição de sentidos de expressões linguísticas, em diferentes fatos de linguagem, em materialidades diversas.

A fim de levarmos a cabo a tarefa proposta neste artigo, além dos pressupostos teóricos citados acima, serão executados os procedimentos de análise da SA, a reescritura e a articulação e a partir do Domínio Semântico de Determinação (DSD), poderemos representar como se dão essas relações, como veremos na seção a seguir. Utilizaremos, também, o mecanismo de paráfrase que consiste em medir os limites interpretativos através da substituição pertinente de um termo por outro que possibilite sustentar determinados sentidos no acontecimento.

\section{Semântica do Acontecimento: teoria e procedimentos de análise}


A SA, teoria semântica enunciativa proposta pelo professor da Unicamp Eduardo Guimarães (2002, 2007, 2009, 2018), considera: “[...] o enunciado como unidade semântica de análise, definida por sua relação de integração ao texto" (GUIMARÃES, 2018 , p. 8). Em outras palavras, para a SA o texto é uma dispersão de sentidos, pois é na enunciação que os sentidos são constituídos e o enunciado, por sua vez, é tratado como integrado a um texto.

Para compreendermos como esses sentidos são constituídos é fundamental ter em mente que a SA coloca de saída a questão do sujeito que enuncia, pois parte dos pressupostos da opacidade da língua e do sujeito ou seja, a língua não é transparente e sua relação com o real é histórica. Nessa perspectiva, o sujeito também não é transparente e não possui controle algum sobre os sentidos daquilo que diz, uma vez que, em nosso escopo teórico, o sujeito não sendo origem do sentido é tomado por ele e é agenciado a dizer o que diz pelo espaço de enunciação: “o Locutor só é Locutor enquanto falante determinado por este espaço político do dizer, o espaço de enunciação" (GUIMARÃES, 2009, p. 50).

Considerando os conceitos discutidos até aqui, podemos dizer que a enunciação consiste em um acontecimento de linguagem e é caracterizada por uma relação do sujeito com a língua, no entanto, é importante ressaltar que essa relação é uma prática política, pois instaura o conflito no centro do dizer (GUIMARÃES, 2002b, p. 8).

Um conceito fundamental da SA que utilizaremos para este trabalho é o conceito de político. Para a SA o político é a base das relações humanas e tais relações se dão por intermédio da linguagem. Guimarães considera o político como uma contradição de uma normatividade que estabelece desigualmente uma divisão do real e a afirmação de 
pertencimento dos que não estão incluídos nesta divisão desigual (GUIMARÃES, 2002, p. 15-16).

Para melhor compreendermos essa questão é importante considerarmos que o acontecimento de linguagem se dá no espaço de enunciação, conceito que Guimarães apresenta como: "[...] um espaço regulado e de disputas pela palavra e pelas línguas, enquanto espaço político" (GUIMARÃES, 2002, p. 18), isto é, corresponde a um espaço de relação entre línguas e falantes, sendo esse espaço caracterizado por uma disputa incessante pela língua numa relação de inclusão/exclusão, posto que essa divisão política nunca é estanque, pois há uma busca constante pelo direito de falar. Dessa maneira, o falante tomado pelo espaço de enunciação é agenciado a falar. Deste modo, podemos dizer então que a enunciação nada tem a ver com a intenção do sujeito que enuncia, visto que o acontecimento de linguagem agencia o sujeito a dizer o que diz, e, ao tratarmos dessa questão, devemos considerar além das relações de linguagem, elementos como o lugar social e a História (GUIMARÃES, 2018, p. 45).

Outro conceito fundamental a ser mobilizado é o de temporalidade. Conforme já dito, o sentido se dá no acontecimento da linguagem e, para que isso ocorra, a enunciação instaura uma temporalidade que é diferente de uma temporalidade cronológica, ou de uma temporalidade instaurada pelo sujeito. $\mathrm{O}$ acontecimento instaura sua própria temporalidade. A enunciação instaura um presente e para constituir sentido, a partir das relações de linguagem contidas no enunciado, remete a um memorável que não é formado por lembranças pessoais, mas por enunciações passadas. Essas memórias de sentidos de enunciações passadas são projetadas para o futuro, ou seja, para possíveis interpretações: 


\begin{abstract}
A temporalidade do acontecimento constitui o seu presente e um depois que abre o lugar dos sentidos, e um passado que não é lembrança ou recordação pessoal de fatos anteriores. O passado é, no acontecimento, rememoração de enunciações passadas, ou seja, se dá como parte de uma nova temporalização, tal como a latência de futuro [...] o acontecimento é sempre uma nova temporalização, um novo espaço de conviviabilidade de tempos, sem a qual não há sentido, não há acontecimento de linguagem, não há enunciação (GUIMARÃES, 2002b, p. 12).
\end{abstract}

No que diz respeito à análise da constituição dos sentidos, a SA faz um deslocamento do conceito de integratividade de Benveniste. Esse deslocamento de integratividade consiste em analisar o sentido de uma expressão linguística não de maneira segmental, mas enquanto integrado a um enunciado e o enunciado enquanto parte de um texto: "[...] consideramos que o sentido de um enunciado é sua relação de integração ao texto em que está" (GUIMARÃES, 2018, p. 42).

A integratividade proposta pela SA não toma o enunciado isoladamente, ou como um processo somatório, mas como lugar de observação da palavra em relação ao texto. Para analisar o sentido de um enunciado de forma integrativa a SA propõe dois procedimentos enunciativos: a reescrituração e a articulação.

O acontecimento da enunciação se dá pelo funcionamento da língua num espaço de enunciação. Assim o acontecimento da enunciação toma o falante, agencia o falante como lugar de enunciação. E isto se faz por um agenciamento político que divide esses lugares de enunciação. Este agenciamento enunciativo produz textos que integram enunciados. Os enunciados significam por esta relação de integração aos textos. Esta relação de integração se configura por dois modos de relação fundamentais: o de articulação, que consiste em uma relação de contiguidade entre os termos do enunciado e o de reescrituração que diz respeito às maneiras que um termo é redito no texto (GUIMARÃES, 2018, p. 75). 
Os conceitos de reescrituração e articulação, propostos por Guimarães, são dois procedimentos enunciativos de análise da constituição de sentidos. As relações de reescrituração são definidas pela maneira como um termo é redito insistentemente em um texto de forma diferente de si. Contudo, diferentemente das relações de articulação, as relações de reescritura não necessariamente são de contiguidade, podendo acontecer entre elementos à distância dentro do texto:

A reescrituração é uma operação que significa, na temporalidade do acontecimento, o seu presente. A reescrituração é a pontuação constante de uma duração temporal daquilo que ocorre. $E$ ao reescriturar, ao fazer interpretar algo diferente de si, este procedimento atribui (predica) algo ao reescriturado. E o que ele atribui? Aquilo que a própria reescrituração recorta como passado, como memorável (GUIMARÃES, 2002b, p. 28).

A reescrituração pode acontecer de diversas formas: a) por repetição, quando a expressão ou o termo é dito repetidamente, na íntegra, no texto; b) por substituição, quando a expressão ou termo é retomado no texto por outra expressão ou termo; c) por elipse, quando a expressão ou termo é omitido em alguma parte do texto; d) por expansão, quando uma expressão ou termo tem seu sentido ampliado por outra expressão ou termo no texto; e) por condensação, ao contrário da reescritura por expansão, ocorre quando uma expressão ou termo é resumido por outra expressão ou termo.

As diversas formas de reescrituração podem produzir as seguintes relações de sentido: f) sinonímia, quando a reescrituração apresenta uma palavra ou expressão como tendo o mesmo sentido que a outra à qual se liga; g) especificação, quando atribui elementos de sentido ao reescriturado pela expressão que o reescritura; h) desenvolvimento, quando produz um desenvolvimento do sentido da expressão ou termo 
reescriturado; i) globalização ou totalização, quando o reescriturado determina generalizações; j) enumeração, lista os termos, os enumera, não necessariamente de forma somatória; k) definição, quando estabelece uma relação de definição entre a reescrituração e o reescriturado.

Outro procedimento enunciativo é a articulação que corresponde a "[...] uma relação de contiguidade significada pela enunciação" (GUIMARÃES, 2009, p. 51). Na articulação são percebidas relações de predicação e complementação - relação determinante/determinado (GUIMARÃES, 2018, p. 80).

A articulação pode acontecer de três modos distintos: 1) por dependência, quando os elementos contíguos se organizam por uma relação que constitui no conjunto um só elemento; 2) por coordenação, quando se apresenta por um processo de acúmulo de elementos numa relação de contiguidade; 3) por incidência, quando há relação entre um elemento e outro sem uma relação de dependência estabelecida (GUIMARÃES, 2009, p. 51).

As relações de sentido analisadas por intermédio dos procedimentos de reescrituração e articulação são representadas pelo DSD (Domínio Semântico de Determinação) que é caracterizado por “[...] uma interpretação do próprio processo de análise e deve ser capaz de explicar o funcionamento do sentido da palavra no corpus especificado" (GUIMARÃES, 2007, p. 81). Essas relações de sentido são demonstradas por meio de representações gráficas, por sinais específicos $(-, \perp, T, F$,$) para a relação de$ determinação, além de (----------) para a relação de sinonímia e (__ relação de antonímia, propostos por Guimarães. 
No tocante à paráfrase, pode-se considerá-la com um mecanismo de análise, um teste em que o analista lança mão para interpretar as relações de sentido que se dão por meio das reescrituras e articulações:

\begin{abstract}
A paráfrase é um teste. A partir de determinado acontecimento, o analista testa as possibilidades de paráfrase para entender os sentidos de determinada enunciação; testa a performatividade do enunciado. Isso significa que, em determinado enunciado, moradia pode ser parafraseado por residência, ao passo que em outro, moradia e residência são itens distintos (SOUZA, 2019, p. 35).
\end{abstract}

\title{
Análises dos sentidos de "professor" em propagandas do MEC
}

Antes de iniciarmos as análises propriamente ditas, faz-se necessário explicar como as materialidades analisadas foram selecionadas. Como dito anteriormente, a SA parte do pressuposto do enunciado enquanto parte de um texto e para isso é necessário um procedimento de análise apropriado, como bem apontado por Guimarães, que toma como procedimento de trabalho a sondagem que implica em encontrar acontecimentos de enunciação que sejam relevantes para reflexão sobre a linguagem e seu modo de produzir sentido.

A sondagem é uma maneira de "eleger" enunciados a serem estudados a partir de uma pergunta. No caso, temos duas perguntas a serem respondidas neste trabalho:

a) Quais os sentidos de professor nas três propagandas veiculadas pelo MEC?

b) Como se configura o político nas relações de sentido ao analisarmos o termo professor?

A partir das perguntas, o procedimento de sondagem tem o propósito de encontrar um enunciado em um recorte do acontecimento de enunciação e, assim, 
explorar esse enunciado enquanto elemento deste recorte e enquanto integrado ao texto, considerando que recorte para a SA é um fragmento do acontecimento da enunciação: "Pelo recorte as formas linguísticas aparecem como correlacionadas em virtude de terem a mesma relação com o acontecimento, independente da posição na sequência" (GUIMARÃES, 2018, p. 75-76).

Feito isto, selecionamos três propagandas, realizamos a transcrição direta de cada uma delas e as organizamos da seguinte forma: (En1) "Eu quero ser professora, é o que eu amo" corresponde à análise da propaganda O Novo Ensino Médio vai deixar o aprendizado mais estimulante e compativel com a sua realidade!, campanha veiculada pelo MEC em 2016 sobre a reforma curricular do ensino médio; (En2) "Quem dedica a vida a ensinar" diz respeito à análise da propaganda veiculada pelo MEC em 2016 sobre a abertura de 105 mil vagas para formação de professores que não possuem formação na disciplina que ensinam, Formação de professores; (En3) "Seja um professor", que corresponde à análise da campanha Valorização do professor, realizada pelo MEC em 2009 para incentivar a licenciatura no Brasil. Seguem abaixo as respectivas análises.

Quadro 1 - (En1) Eu quero ser professora, é o que eu amo.

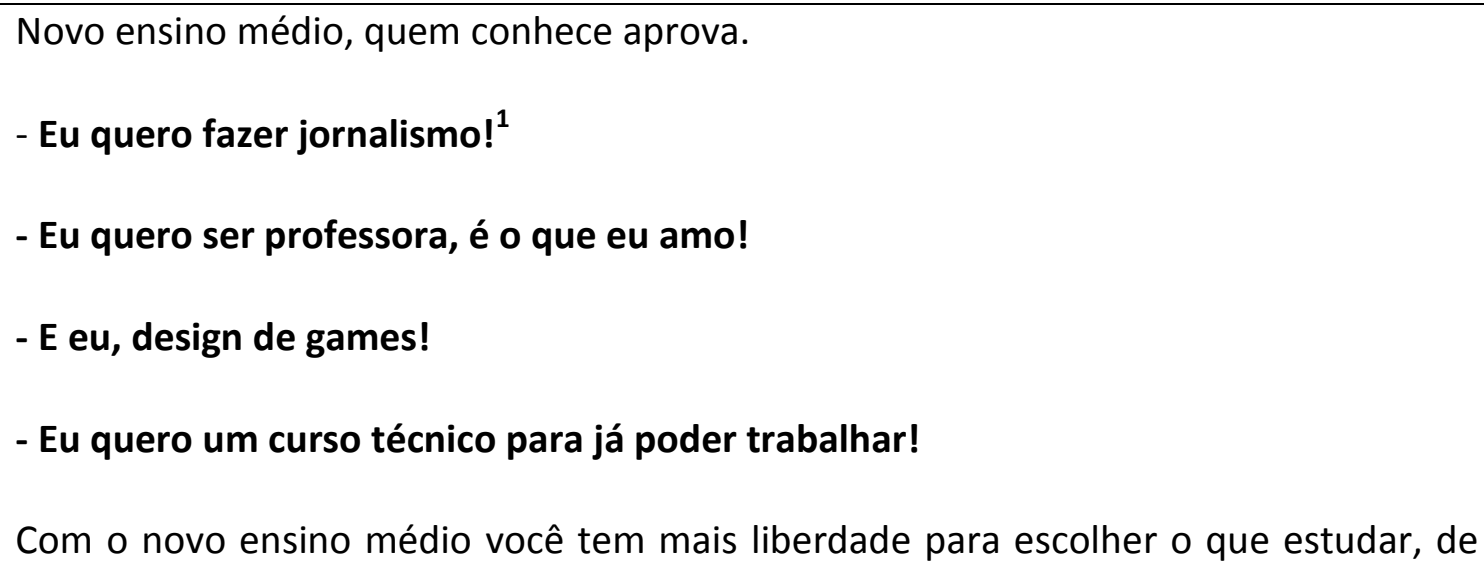


acordo com a sua vocação.

É a liberdade que você queria para decidir o seu futuro.

Quem conhece o novo ensino médio, aprova.

Acesse o site e saiba mais. Ministério da educação, governo federal. Ordem e progresso.

Fonte: <https://www.youtube.com/watch?v=7_FdhibiOyQ>

Em (En1), o termo "professora" está articulado por coordenação aos termos "eu quero ser" e "é o que eu amo" e se articula por coordenação as demais expressões, as quais: “Eu quero fazer jornalismo; E eu, design de games; Eu quero curso técnico para já poder trabalhar". Observamos a partir dessas relações de linguagem que as únicas carreiras que tem suas escolhas justificadas são o ensino técnico e a docência. O ensino técnico é para "já poder trabalhar" e a professora quer seguir essa carreira "por amor". Isso nos leva a possível interpretação de que por serem carreiras desprestigiadas, ao serem escolhidas necessitam justificativas, pois o ensino técnico tem como objetivo formar mão de obra, à medida que só o amor justifica escolher a carreira docente. Podemos observar como essas relações são estabelecidas por meio dos três DSDs abaixo:

Quadro 2 - DSD de professor (1)

professor $F$ amor

Fonte: elaboração própria 
No primeiro DSD, "professor" é determinado por amor. O enunciado ao instaurar a temporalidade remete ao memorável da docência como um exercício de amor e doação. A dar continuidade na análise, vejamos o próximo DSD:

Quadro 3 - DSD de curso técnico

\section{Curso técnico - trabalho}

Fonte: elaboração própria

No DSD acima, "curso técnico" é determinado por trabalho e remete ao memorável do tecnicismo e da formação de mão de obra para atender ao mercado de trabalho. Seguimos a análise com o terceiro DSD:

Quadro 4 - DSD de professor (2)

professor F não é trabalho

Fonte: elaboração própria

O termo "professor" é determinado por não é trabalho, pois o sentido de amor sobrepuja o sentido profissional. Ser profissional no enunciado que acabamos de analisar tem um sentido utilitarista, pois está diretamente relacionado ao ensino técnico, enquanto a docência, longe disso, é um exercício de amor.

Quadro 5 - (En2) Quem dedica a vida a ensinar Investir na educação é investir na formação de quem dedica a vida a ensinar.

Por isso, o governo federal está ampliando o acesso aos cursos de licenciatura 
ou complementação pedagógica para professores de todo o Brasil.

Serão 105 mil novas vagas nas melhores instituições federais do país, permitindo que os professores obtenham uma formação completa com licenciatura na disciplina que ensinam. Professor, a rede de universidades públicas é para você. Não perca tempo.

Inscreva-se até 05 de maio pelo site.

Fonte: <https://www.youtube.com/watch?v=D4IhSs2Gq4s>

Em (En2) "quem dedica a vida a ensinar" é uma reescritura por expansão do termo "professor" que produz uma especificação, pois professor é aquele que dedica sua vida a ensinar. Essa reescritura está articulada por coordenação às expressões "investir na educação" e "investir na formação". O que nos chama a atenção é que no enunciado investir na educação é investir na formação do professor porque dedica sua vida a ensinar e não por questões relativas à qualificação profissional propriamente dita. As relações de reescritura instauram sentidos de docência como exercício de amor e abnegação. Seguimos com os DSDs abaixo:

\section{Quadro 6 - DSD de formação}

formação $\nmid$ investir na educação

Fonte: elaboração própria

O termo "formação" determina "investir na educação" e nos remete ao sentido de que a formação de professores é fundamental para uma educação de qualidade. Continuemos a representar essas relações de sentidos no próximo DSD: 


\section{Quadro 7 - DSD de professor (3)}

Professor Fabnegação

Fonte: elaboração própria

O termo "professor" é determinado por "abnegação" e remete ao memorável da docência como sacerdócio, já que dedicar a vida a ensinar é abrir mão de si para dedicarse ao ensino, o que exige abnegação e doação. Continuemos com a análise do enunciado no próximo recorte: "Por isso, o governo federal está ampliando o acesso aos cursos de licenciatura ou complementação pedagógica para professores de todo o Brasil".

Nesse recorte o termo "professores" é uma reescritura por condensação da expressão "de quem dedica a sua vida a ensinar" e está articulado por dependência à expressão "de todo o Brasil", ao passo que, também, se articula por coordenação a "cursos de complementação pedagógica e licenciatura", que por sua vez se articulam por coordenação com "governo federal está ampliando". Essas relações enunciativas nos levam a interpretar que o governo está ampliando cursos de formação para professores que não possuem nível superior, para professores que possuem licenciatura, mas atuam no ensino de disciplina de outra área ou para professores que já possuem nível superior, mas em área diferente da educação. Abaixo, o quadro DSD:

Quadro 8 - DSD de professores

Professores Fcursos de complementação pedagógica e licenciatura

Fonte: elaboração própria 
O termo "professores" é determinado por cursos de complementação pedagógica e licenciatura e essas relações remetem ao memorável da desvalorização, pois há professores sem formação específica para sua área de atuação. A continuar com nossa análise, vejamos no recorte a seguir esses sentidos serem sustentados: "Serão 105 mil novas vagas nas melhores instituições federais do país, permitindo que os professores obtenham uma formação completa com licenciatura na disciplina que ensinam. Professor, a rede de universidades públicas é para você".

No último recorte o termo "professores" é uma reescritura por repetição de "professores", uma reescritura por substituição de "professor" e de "você", e também está articulado por coordenação com a expressão "vagas nas melhores instituições federais do país" que é reescriturada por substituição pelo termo "rede de universidades públicas". As reescrituras de "professor" também se articulam por coordenação à expressão "obtenham uma formação completa" que é uma reescritura por expansão de "licenciatura na disciplina que ensinam". O enunciado instaura sentidos de professores que atuam sem formação específica na disciplina que lecionam. Observemos abaixo a representação dessas relações:

Quadro 9 - DSD de Professores que lecionam sem formação universidades públicas

Formação 


\section{Professores que lecionam sem formação}

Fonte: elaboração própria

O termo "universidades públicas" determina "formação", que determina "professores que lecionam sem formação". Os sentidos instaurados pelas relações de linguagem no recorte nos permitem interpretar que professores lecionam sem ter formação e que para resolver essa questão as vagas para formação desses profissionais foram ampliadas e são ofertadas pelas universidades públicas.

\section{Quadro 10 - (En3) Seja um professor}

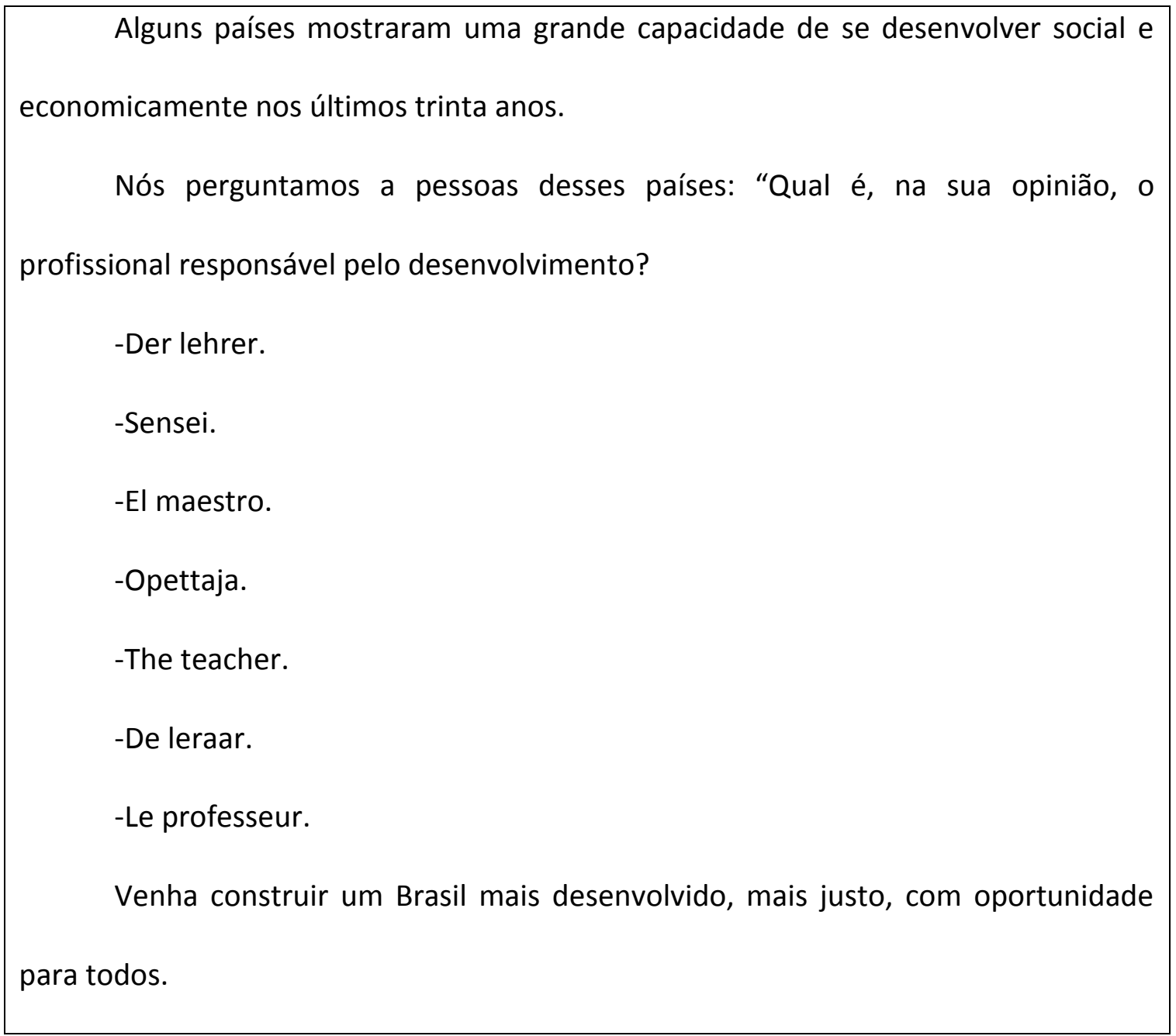




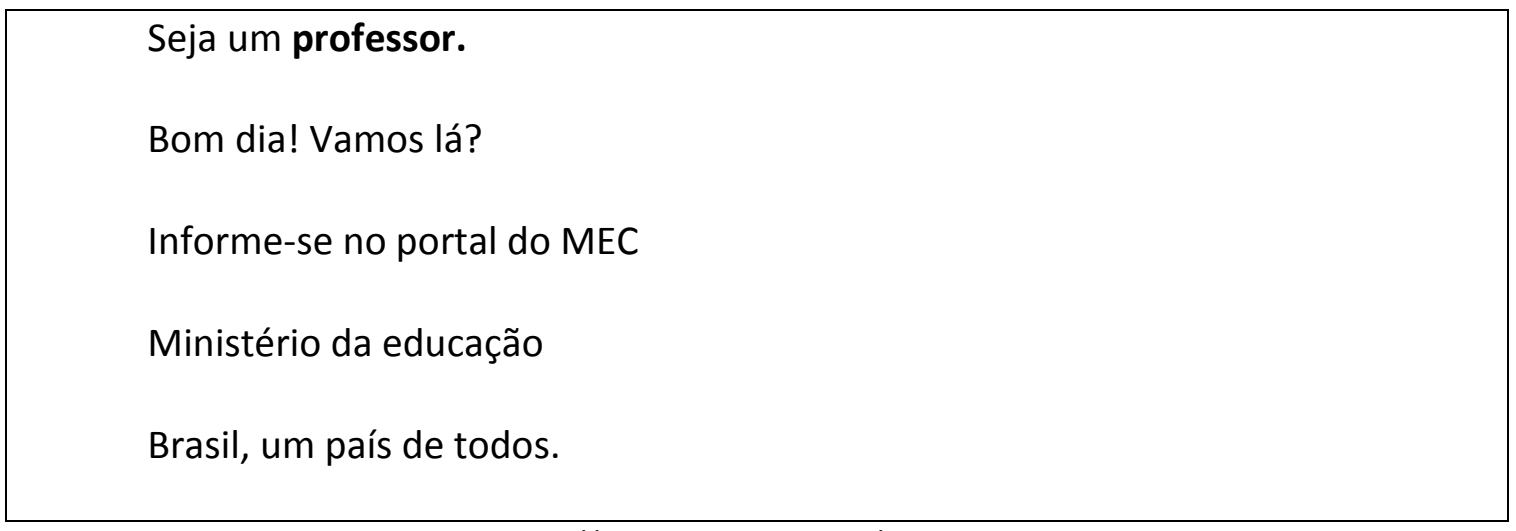

Fonte: <https://www.youtube.com/watch?v=7|BWfCl9flg>

No enunciado, os termos "der lehrer", "sensei", "el maestro", "opettaja, the teacher", "de leraar" e "le professeur" são termos em alemão, japonês, espanhol, finlandês, inglês, holandês e francês, respectivamente, e todos podem ser traduzidos em português como "professor", portanto, são reescriturações por substituição deste termo que produz uma relação de sinonímia. Há outra reescrituração por substituição de "professor" pelo termo "profissional" o que produz uma especificação. Todas essas reescrituras estão articuladas por coordenação à "perguntamos a pessoas desses países: Qual é, na sua opinião, o profissional responsável pelo desenvolvimento?".

Por meio das relações de reescritura e articulação observadas neste acontecimento podemos interpretar que o professor é responsável pelo desenvolvimento social e econômico desses países e que a sua importância é reconhecida pela sociedade. A representar essas relações temos o DSD:

Quadro 11 - DSD de países desenvolvidos

Professor $\nmid$ Países desenvolvidos

Fonte: elaboração própria 
O termo "professor" determina "países desenvolvidos" e nos remete ao memorável de sentidos que os países são desenvolvidos porque valorizam e investem no professor.

A dar seguimento à análise, a expressão "venha construir um Brasil mais desenvolvido, mais justo, com oportunidade para todos" se articula por coordenação a "seja um professor", sendo que "professor" é uma reescritura por repetição. Os sentidos instaurados por essas relações enunciativas remetem ao professor como fundamental para o desenvolvimento do Brasil e para uma sociedade mais justa, sendo essas as razões pelas quais vale a pena ser professor, e isso se sustenta por meio do apelo "seja um professor".

Quadro 12 - DSD de seja um professor

Seja um Professor $\nmid$ Brasil desenvolvido e justo

Fonte: elaboração própria

A expressão "seja um professor" determina "Brasil desenvolvido e justo" e a temporalidade instaurada pelo acontecimento remete ao memorável da importância social do professor, mas também remete à resistência em escolher a docência como carreira no Brasil, e isso se sustenta por meio das relações de articulação na expressão "Venha construir um Brasil mais desenvolvido, mais justo, com oportunidade para todos". "Seja um professor" instaura sentidos de que para que o Brasil também se desenvolva economicamente e socialmente é importante que as pessoas escolham a carreira docente. 


\section{Considerações finais}

Nas análises realizadas neste trabalho podemos observar como se constituem os sentidos de "professor" e como se configura o político nas propagandas veiculadas pelo MEC. Notamos em (En1) que sentidos de desprestígio estão presentes quando a escolha pela carreira docente precisa ser justificada pelo amor.

Ao longo da análise em (En2), podemos interpretar que investir na educação é investir na formação de professores e, para tanto, o governo investe na ampliação de vagas nas universidades, porém, a existência de professores que ainda exercem sua profissão sem formação específica indica que os investimentos em educação não têm sido muito efetivos, o que nos remete a sentidos de precarização da docência. Esses sentidos são sustentados por outro sentido também instaurado pelo mesmo acontecimento que é o de docência como sacerdócio, ao passo que esse sentido de docência sobrepuja o sentido profissional. Podemos assim perceber sentidos bastante conflitantes, pois ao mesmo tempo em que é importante investir na formação de professores, a docência não se configura como profissão, mas como sacerdócio.

Em (En3) há o reconhecimento de que o professor é um profissional importante para o desenvolvimento do Brasil e para uma sociedade mais justa e para sustentar esses sentidos o memorável dos professores como responsável pelo desenvolvimento de diversos países é recortado o que nos permite uma futuridade interpretativa de que o desenvolvimento de um país e uma sociedade mais justa são motivos pelos quais vale a pena ser professor. Todavia, o acontecimento também remete à resistência em escolher a docência como carreira no Brasil devido à desvalorização profissional do professor. 
Dessa forma, através das análises, observamos como se dá o político nas relações de sentido. A corroborar com nossa hipótese, a importância do professor é reconhecida nos enunciados analisados quando se aponta para a importância em investir em sua formação ou porque é considerado a base para uma sociedade mais desenvolvida e justa, porém, sentidos de desvalorização do professor são percebidos quando se justifica escolher a carreira docente por amor ou sentidos de afetividade e sacerdócio sobrepujam os sentidos da docência como profissão. Assim, nota-se ao longo desta discussão, que os sentidos não são fixos, longe disso, eles são dados pela enunciação em cada acontecimento de linguagem e estão em constante conflito.

\section{Referências}

BENVENISTE, E. Problemas de linguística geral. Tradução Maria da Glória Novak e Luiza Neri. São Paulo: Ed. da Universidade de São Paulo, v. 8, 1976.

GUIMARÃES, E. Semântica do acontecimento. Campinas, SP: Pontes. 2002.

A enumeração: funcionamento enunciativo e sentido. Cadernos de Estudos Linguísticos, Campinas, v. 51, n. 1, p. 49-68, 2009.

Os limites do sentido: um estudo histórico e enunciativo da linguagem. Campinas, SP: Editora RG. 4. ed. 2010.

Análise de texto: procedimentos, análises, ensino. Campinas, SP: Editora RG, 2011.

Semântica: enunciação e sentido. Campinas, SP: Pontes, 2018.

PAYER, Maria Onice. Linguagem e sociedade contemporânea - sujeito, mídia, mercado. Revista Rua, Campinas, SP, v. 11, n. 1, p. 09-25. set. 2005.

SOUZA, D. S. Sentidos de impeachment no caso Dilma Rousseff: um estudo semântico. Dissertação (Mestrado em Linguística). Universidade Estadual do Sudoeste da Bahia, Vitória da Conquista, BA. 2019. 
Lívia Cristina de Souza Sigliani e Adilson Ventura da Silva

Recebido em 31 de agosto de 2019.

Aceite em 10 de dezembro de 2019.

\footnotetext{
${ }^{1}$ Todos os grifos são nossos.
} 